UDC 534.121.1

V.L. Karlash, Dr.Sc.

S. P. Timoshenko Institute of Mechanics, Nat. Acad. Sci. of Ukraine,

3, Nesterov Str. 03057, Kyiv, Ukraine, e-mail: karlashv@ukr.net.

\title{
Energy losses in piezoceramic resonators and its influence on vibrations' characteristics
}

This paper is devoted to analyze of the modern achievements in energy loss problem for piezoceramic resonators. In parallel a new simple methodic of an experimental determination of energy losses and coupling coefficients is presented and author's opinion why mechanical quality is different on resonance and anti-resonance is gave. The reason lies in "clamped" capacity and electromechanical coupling factor's value. The better electromechanical coupling the stronger capacity "clamping" and the higher its influence on anti-resonant frequency and quality. Reference 36, figures 4, tables 3 .

Keywords: piezoceramic resonators, energy losses, electromechanical coupling factors, resonance/anti-resonance mechanical quality.

\section{Introduction}

Piezoceramic construction elements, while performing similar or better than electromagnetic ones, are more suitable for miniaturization's purpose [31 - 33]. When uniform mechanic stress is applied in a non-center symmetric crystal or polarized piezoceramic's sample there is a movement of positive and negative ions with respect to each other, creating an electric charge at the surface. This is a direct piezoelectric effect - a conversion of mechanical energy into electrical energy. When electric field is applied to the sample an elastic strain is produced. This is a converse piezoelectric effect - a conversion of an electric energy into mechanical energy. When an alternating electric field is applied mechanic vibrations are induced, which at appropriate frequency cause mechanical resonance with great strains and stresses. A phenomenon of strain increasing due to accumulated electric energy is called a piezoelectric resonance $[1,6,9,13,28$, 29]. Both direct and converse piezoelectric effects are linear physical phenomena with respect to induce fields.

The internal physical processes nature in piezoceramic constructive elements drives to the fact that displacements, strains, stresses, admittance and impedance have both real and imaginary parts $[9,13,14,28,29]$. It is impossible to calculate any amplitude without accounting the energy losses $[13,29]$. The electromechanical coupling firstly was introduced in analyze by W. Voigt [35]. An energy losses problem appears in pioneer's works of a XXth century beginning of S. Butterworth [2]; W. G. Cady [3]; K. S. Van Dyke [5]; S. L. Quimby [27]; D. E. Dye [4] etc. Energy losses were accounted as viscosity, decaying decrements or acoustic radiation. Later W. P. Mason introduced in equivalent electric network an additive loss resistor [22]. In 60th and 70-th years an idea of complex coefficients was proposed and back-grounded by S. E. Land et al [21], G. E. Martin [23], R. Holland [7] etc. In analyze energy losses now include three imaginary parts: elastic, dielectric and piezoelectric ones [7, $9,13,23,28,29]$ Loss problem especially rises in high frequency $(20-100 \mathrm{MHz})$ applications where thickness reaches $200 \mathrm{mkm}$ or less [24].

The analytic solutions for electroelastic vibrations of simple geometric form bodies such as bars, rods, disks, circular or cylindrical rings etc $[7,13$, $23,28]$ are used in standards for determining real parts of the dielectric, elastic and piezoelectric coefficients $[6,8,28]$. Imaginary parts usually are determined on maxima / minima admittance, first proposed by Martin [23]. In [11, 12].it was proposed to use for such aims thin piezoceramic disk's radial vibrations. Very important role in energy losses belongs to mechanic quality factor $Q$, which differs for resonance and anti-resonance $[25,26]$.

An investigation of energy losses in piezoelectric materials was, is and will be during long time with important scientific problem

\section{Elastic, dielectric and piezoelectric energy losses in piezoceramics and their measuring}

In analyze the piezoceremic elements are described by various elastic, dielectric and piezoelectric coefficients or modulus, which are represented mostly in complex form $[7,9,14,29]$

$$
\begin{gathered}
a=a_{1}-j a_{2}=a^{\prime}-j a^{\prime \prime}=a_{10}\left(1-j a_{1 m}\right) ; \\
\frac{a_{2}}{a_{1}}=\frac{a^{\prime \prime}}{a^{\prime}}=a_{1 m}=\tan \xi .
\end{gathered}
$$

Here in common view as $a$ it is noted such electroelastic coefficients as stiffness $c_{i j}$, compliances $s_{k l}$, piezomodulus $d_{n m}$, coupling factors $k_{t r}$, 
dielectric constants $\varepsilon_{p q}$ etc. Expressions for elastic displacements $U$, strains $\varepsilon$ and stresses $\sigma$, electric powers $P$, admittances $Y$ or impedances $Z$, dimensionless frequencies $x$ are complex too [13]. For imaginary parts of complex modulus were derived next restricting inequalities $[7,9,28]$

$$
\begin{gathered}
\mathrm{s}_{11}^{\prime \prime}, \mathrm{s}_{33}^{\prime \prime}, \mathrm{s}_{44}^{\prime \prime}, \mathrm{s}_{66}^{\prime \prime}, \varepsilon_{11}^{\prime \prime}, \varepsilon_{33}^{\prime \prime} \geq 0 ; \\
\mathrm{s}_{11}^{\prime \prime} \geq\left|\mathrm{s}_{12}^{\prime \prime}\right| ; \\
\mathrm{s}_{11}^{\prime \prime} \mathrm{s}_{33}^{\prime \prime} \geq\left(\mathrm{s}_{13}^{\prime \prime}\right)^{2} \\
\mathrm{~s}_{11}^{\prime \prime} \varepsilon_{33}^{\prime \prime} \geq\left(\mathrm{d}_{31}^{\prime \prime}\right)^{2} ; \\
\mathrm{s}_{33}^{\prime \prime} \varepsilon_{33}^{\prime \prime} \geq\left(\mathrm{d}_{33}^{\prime \prime}\right)^{2} \\
\mathrm{~s}_{33}^{\prime \prime}\left(\mathrm{s}_{11}^{\prime \prime}+\mathrm{s}_{12}^{\prime \prime}\right) \geq 2\left(\mathrm{~s}_{13}^{\prime \prime}\right)^{2} \\
\varepsilon_{33}^{\prime \prime}\left(\mathrm{s}_{11}^{\prime \prime}+\mathrm{s}_{12}^{\prime \prime}\right) \geq 2\left(\mathrm{~d}_{31}^{\prime \prime}\right)^{2}
\end{gathered}
$$

All notations are taken from $[13,29]$. These inequalities show that energy losses imaginary parts in piezoelectric materials are not random but are coupled each other. It means that perfect in elastic or dielectric properties piezoelement has perfect electroelastic properties too.

Analytic calculations and experimental data show that losses influences on vibrations are different at resonance/anti-resonance phenomena. All modern methods of loss tangents determination base on maxima/minima admittance measure at first rod or bar mode of vibration [7, 24].

It may be shown that piezoelectric resonator's admittance is inter-electrode capacity $C_{0}$ conductivity produced on anti-resonance $\Delta_{\mathrm{a}}(\mathrm{x})$ to resonance $\Delta(\mathrm{x})$ determinants ratio

$$
\mathrm{Y}=\mathrm{j} \omega \mathrm{C}_{0} \frac{\Delta_{\mathrm{a}}(\mathrm{x})}{\Delta(\mathrm{x})},
$$

$x-$ is dimensionless frequency, which depend upon geometric sample's form.

Next formulae were derived for thin rod with thickness polarization, shot cylindrical ring and high cylindrical shell with radial polarization accordingly [28]

$$
\begin{aligned}
& Y_{b}=j \omega C_{0}\left[1-k_{31}^{2}+\frac{k_{31}^{2} \sin x}{x \cos x}\right]=j \omega C_{0} \frac{\Delta_{a}(x)}{\Delta(x)}, \\
& \Delta(x)=\cos (x), \Delta_{a}(x)=\left(1-k_{31}^{2}\right) \Delta(x)+k_{31}^{2} \sin x / x \\
& Y_{s k}=j \omega C_{0}\left[1-k_{31}^{2}+\frac{k_{31}^{2} \omega_{r}^{2}}{\omega_{r}^{2}-\omega^{2}}\right]=j \omega C_{0} \frac{\Delta_{a}(x)}{\Delta(x)}, \\
& \Delta(x)=\omega_{r}^{2}-\omega^{2}, \Delta_{a}(x)=\left(1-k_{31}^{2}\right) \Delta(x)+k_{31}^{2} \omega_{r}^{2} \\
& Y_{h k}=j \omega C_{0}\left[1-k_{p}^{2}+\frac{(1+v) k_{p}^{2} \omega_{r}^{2}}{2\left(\omega_{r}^{2}-\omega^{2}\right)}\right]=j \omega C_{0} \frac{\Delta_{a}(x)}{\Delta(x)}, \\
& \Delta(x)=\omega_{r}^{2}-\omega^{2}, \Delta_{a}(x)=\left(1-k_{p}^{2}\right) \Delta(x)+(1+v) k_{p}^{2} \omega_{r}^{2} / 2 .
\end{aligned}
$$

Here: $j$ is an imaginary unit, $\omega$ is an angular frequency, $\omega_{r}$ - resonant angular frequency, $k_{31}-$ transverse coupling coefficient, $k_{p}$ - planar coupling coefficient, $v$-Poisson ratio.

After substituting (1) in (4) G. E. Martin obtained approximate formulae [23]

$$
\begin{gathered}
Y_{m}=\frac{8 \omega_{m} C_{0} k_{31}^{2}}{\pi^{2} s_{11 m}} \\
Y_{n}=\omega_{n} C_{0}\left[\varepsilon_{33 m}-2 d_{31 m}+\frac{\pi^{2} s_{11 m}}{8 k_{31}^{2}}\right]
\end{gathered}
$$

and

$$
\begin{gathered}
s_{11 m}=\frac{16 f_{m} C_{0} k_{310}^{2}}{\pi Y_{m}}, \\
d_{31 m}=\frac{\varepsilon_{33 m}}{2}+\frac{\pi^{2} s_{11 m}}{16 k_{310}^{2}}-\frac{Y_{n}}{4 \pi f_{n} C_{o}}
\end{gathered}
$$

Coupling coefficient $k_{31}$ is determined as [26, 28]

$$
\frac{k_{310}^{2}}{1-k_{310}^{2}}=\frac{\pi}{2} \frac{f_{n}}{f_{m}} \tan \left[\frac{\left(f_{n}-f_{m}\right) \pi}{2 f_{m}}\right] \text {. }
$$

In a "short" cylindrical ring case dimensionless frequency is $x=\omega / \omega_{r}$ and coefficient $k_{31}$ is determined from relation

$$
k_{310}^{2}=\frac{\omega_{a}^{2}-\omega_{r}^{2}}{\omega_{a}^{2}},
$$

known as Meson's formula [1, 6, 15, 28]. Maxima admittance and mechanic quality are

$$
\begin{gathered}
Y_{m}=\omega_{m} C_{0} k_{310}^{2} Q_{m}=\frac{\omega_{m} C_{0} k_{310}^{2}}{s_{11 m}}, \\
Q_{m}=\frac{Y_{m}}{\omega_{m} C_{0} k_{310}^{2}} .
\end{gathered}
$$

In a "high" cylindrical ring case dimensionless frequency is $x=\omega / \omega_{r}$ and coefficient $k_{p}$ is determined from relation

$$
\frac{2\left(1-k_{p}^{2}\right)}{(1+v) k_{p}^{2}}=\frac{f_{m}^{2}}{f_{n}^{2}-f_{m}^{2}} .
$$

Thin piezoceramic disk's radial vibrations have following admittance $[9,13,29]$

$$
\begin{gathered}
Y_{d s k}=j \omega C_{0}\left[1-k_{p}^{2}+\frac{(1+v) k_{p}^{2} J_{1}(x)}{\Delta(x)}\right]=j \omega C_{0} \frac{\Delta_{a}(x)}{\Delta(x)}, \\
\Delta(x)=x J_{0}(x)-(1-v) J_{1}(x), \\
\Delta_{a}(x)=\left(1-k_{p}^{2}\right) \Delta(x)+(1+v) k_{p}^{2} J_{1}(x) .
\end{gathered}
$$

Dimensionless frequency for disk is $\mathrm{x}=\omega \mathrm{R} \sqrt{\rho \mathrm{s}_{11}^{\mathrm{E}}\left(1-v^{2}\right)}$, where $R-$ is plate's radius, $\rho$ - density. 
After manipulating with complex functions, in [12, 13, and 29] it was obtained

$$
\begin{gathered}
\mathrm{s}_{11 \mathrm{~m}} \approx \frac{4.9 \mathrm{f}_{\mathrm{m} 1} \mathrm{C}_{0} \mathrm{k}_{\mathrm{po}}^{2}}{\mathrm{Y}_{\mathrm{m} 1}}, \mathrm{~d}_{31 \mathrm{~m}} \approx \frac{\mathrm{s}_{11 \mathrm{~m}}+\varepsilon_{33 \mathrm{~m}}}{2}- \\
-\frac{\mathrm{Y}_{\mathrm{n}}}{4 \pi \mathrm{f}_{\mathrm{n} 1} \mathrm{C}_{0}}+\frac{\mathrm{s}_{11 \mathrm{~m}} \mathrm{x}_{\mathrm{n}} \delta_{\mathrm{n}}}{4 \Delta_{\mathrm{n}}} \\
\delta_{\mathrm{n}}=\left(1+\mathrm{k}_{\mathrm{p} 0}^{2}\right) \beta_{\mathrm{n}}+\mathrm{k}_{\mathrm{p} 0}^{2}(1+v) \gamma_{\mathrm{n}} \\
\gamma_{\mathrm{n}}=\left[\mathrm{x}_{\mathrm{n}} \mathrm{J}_{0}\left(\mathrm{x}_{\mathrm{n}}\right)-\mathrm{J}_{1}\left(\mathrm{x}_{\mathrm{n}}\right)\right] / \mathrm{x}_{\mathrm{n}} \\
\beta_{\mathrm{n}}=(1+v) \mathrm{J}_{0}\left(\mathrm{x}_{\mathrm{n}}\right)-\kappa_{0} \mathrm{~J}_{1}\left(\mathrm{x}_{\mathrm{n}}\right)- \\
-\Delta\left(\mathrm{x}_{\mathrm{n}}\right) / \mathrm{x}_{\mathrm{n}}, \Delta_{\mathrm{n}}=\Delta_{\mathrm{a}}\left(\mathrm{x}_{\mathrm{n}}\right)
\end{gathered}
$$

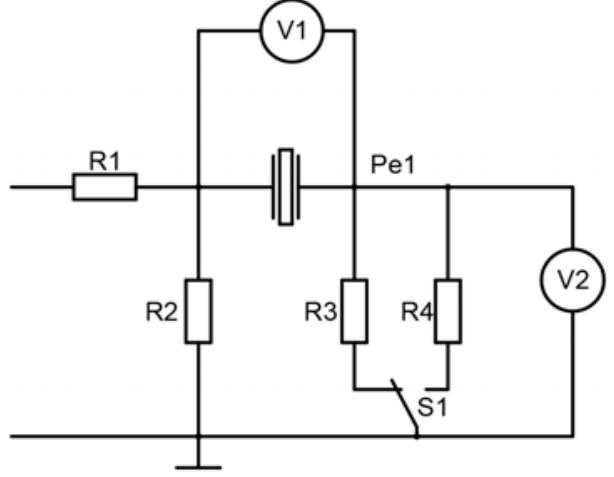

a)

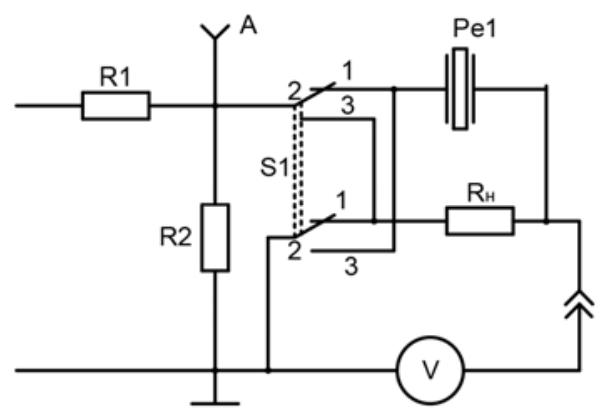

b)

Fig. 1. Meson's four-pole variants

To use these formulae it is necessary to measure maxima/minima admittances and frequencies and to calculate factors $\beta, \delta, \gamma$ at anti-resonance.

The resonance and anti-resonance frequencies are determined in analyze as that frequencies, where phase shifts between sample's voltage and its current are zero $[1-3,6]$. It is not lightly to reach such effect in practice, and resonant frequency $f_{r}$ is identified with maxima admittance frequency $f_{m}$, while anti-resonant frequency $f_{a}$ is identified with minima admittance frequency $f_{n}$.

Two variants of simple experimental networks are presented on Fig 1. The first schema is known as Meson's four-pole [6, 9, 13]. Input voltage divider $R 1, R 2$ matches generator's output with measuring circuit. In parallel to output resistor $R 2$ is included piezoelement $P e$ and loading resistors $R 3$ or $R 4$. Voltmeter $V 1$ measures voltage $U_{p e}$ dropped on piezoelement and voltmeter $V 2$ measures voltage $U_{R}$ dropped on loading resistors Voltage $U_{R}$ is proportional to electrical current $I_{p e}$ in resistor and sample. The ratio of current to voltage is definite as admittance, so that

$$
Y_{p e}=\frac{I_{p e}}{U_{p e}}=\frac{U_{R}}{R U_{p e}} .
$$

In practice formula (15) not may be used in Fig 1, a schema, because do not exist such voltmeter, which may be taken for $V 1$ position. On this reason voltage $U_{p e}$ in this schema determined as difference between input voltage $U_{\text {in }}$ and voltage $U_{R}$. Instead of the exact formula (15) an approximation is used

$$
Y_{p e 1}=\frac{U_{R}}{R\left(U_{\text {in }}-U_{R}\right)} .
$$

When loading resistor and sample change one another, a next approximate formula may be derived

$$
Y_{p e 2}=\frac{\left(U_{\text {in }}-U_{p e}\right)}{R U_{p e}} .
$$

In contrast, the Fig $1, b$ network permits to measure all voltages $U_{p e}, U_{\text {in }}$ and $U_{R}$ in a wide frequency range by single voltmeter $V$ [15]. Voltmeter's input (point " $C$ ") may be connected with voltage divider's output (point " $A$ ") or common for resistor and sample connection (point " $B$ "). In higher switcher's position, as shown on Fig $1, b$, this network is analog to Fig 1, a schema and voltmeter measures $U_{R}$ voltage. When switcher $S 1$ is in lower position, voltmeter measures $U_{p e}$ voltage. This 
schema is able to realize three various loading conditions: 1) constant current, 2) constant sample's voltage, 3) constant input voltage. Experimen- tal data enter to PC and AFCh (amplitudefrequency characteristics) a number of physical parameters are plotted.

Table 1. Dependence of an admittance maxima and resonant frequency upon loading resistor's value

\begin{tabular}{|c|l|l|l|l|l|}
\hline$R_{l}, \mathrm{Ohm}$ & 1,6 & 5,3 & 11,2 & 230 & 993 \\
\hline$f_{r}, \mathrm{kHz}$ & 31,572 & 31,560 & 31,562 & 31,563 & 31,576 \\
\hline$Y_{m}, \mathrm{mS}$ & 131,4 & 124 & 119,6 & 101,4 & 26,36 \\
\hline
\end{tabular}

Table 1 shows that frequencies of admittance maxima have very small dependencies upon loading resistor value but strong for conductivity.

Three measured voltages $U_{p e}, U_{R}$ and $U_{i n}$ create peculiar characteristic triangle and angles between its sides may be calculated with using a cosine theorem (low of cosines) as
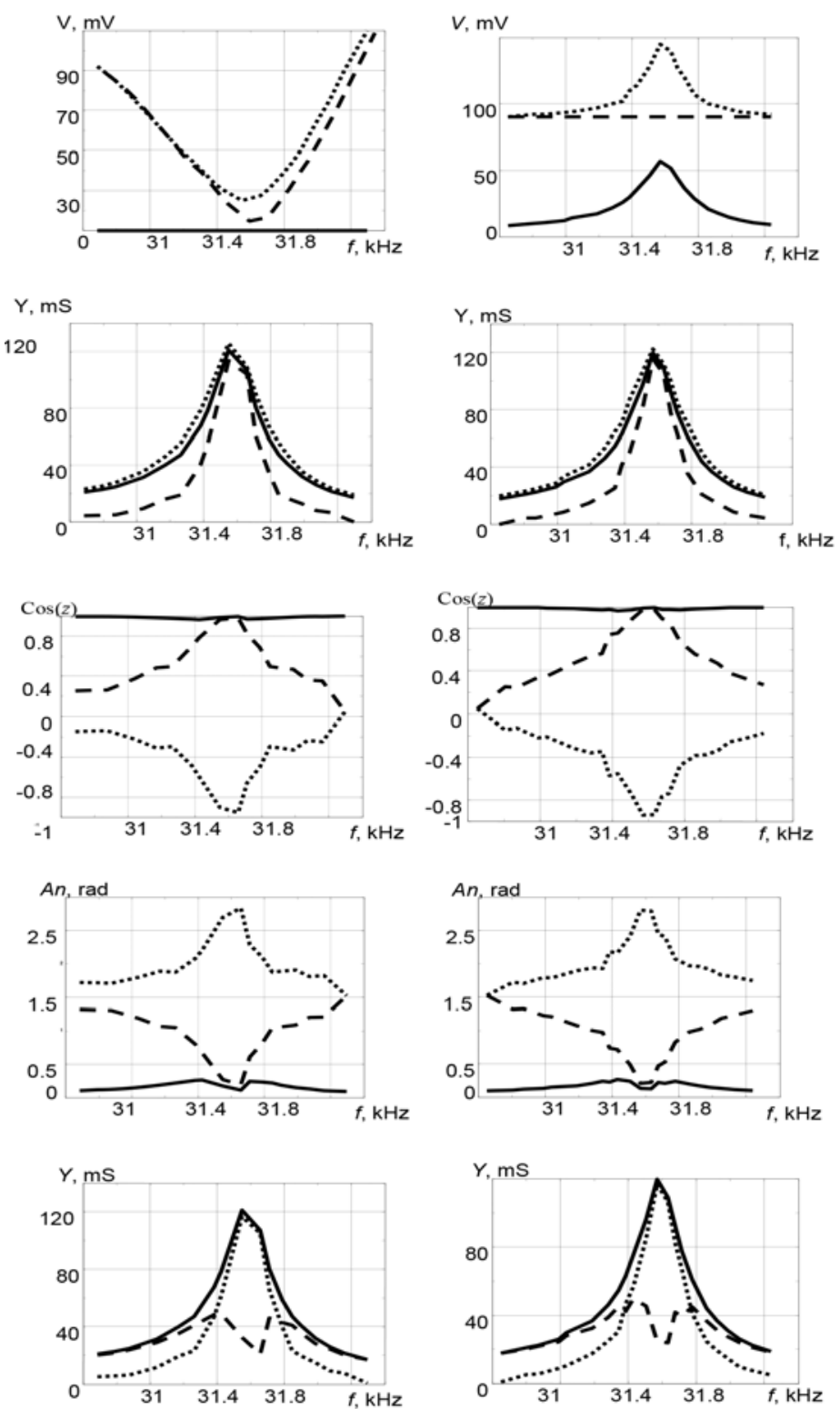

$\cos \alpha=\frac{U_{\mathrm{pe}}^{2}+U_{\mathrm{R}}^{2}-U_{\mathrm{in}}^{2}}{2 \mathrm{U}_{\mathrm{pe}} \mathrm{U}_{\mathrm{R}}}$

$\cos \beta=\frac{U_{\text {in }}^{2}+U_{R}^{2}-U_{p e}^{2}}{2 U_{\text {in }} U_{R}}$

$\cos \gamma=\frac{U_{\text {in }}^{2}+U_{\text {pe }}^{2}-U_{R}^{2}}{2 U_{\text {in }} U_{\text {pe }}}$
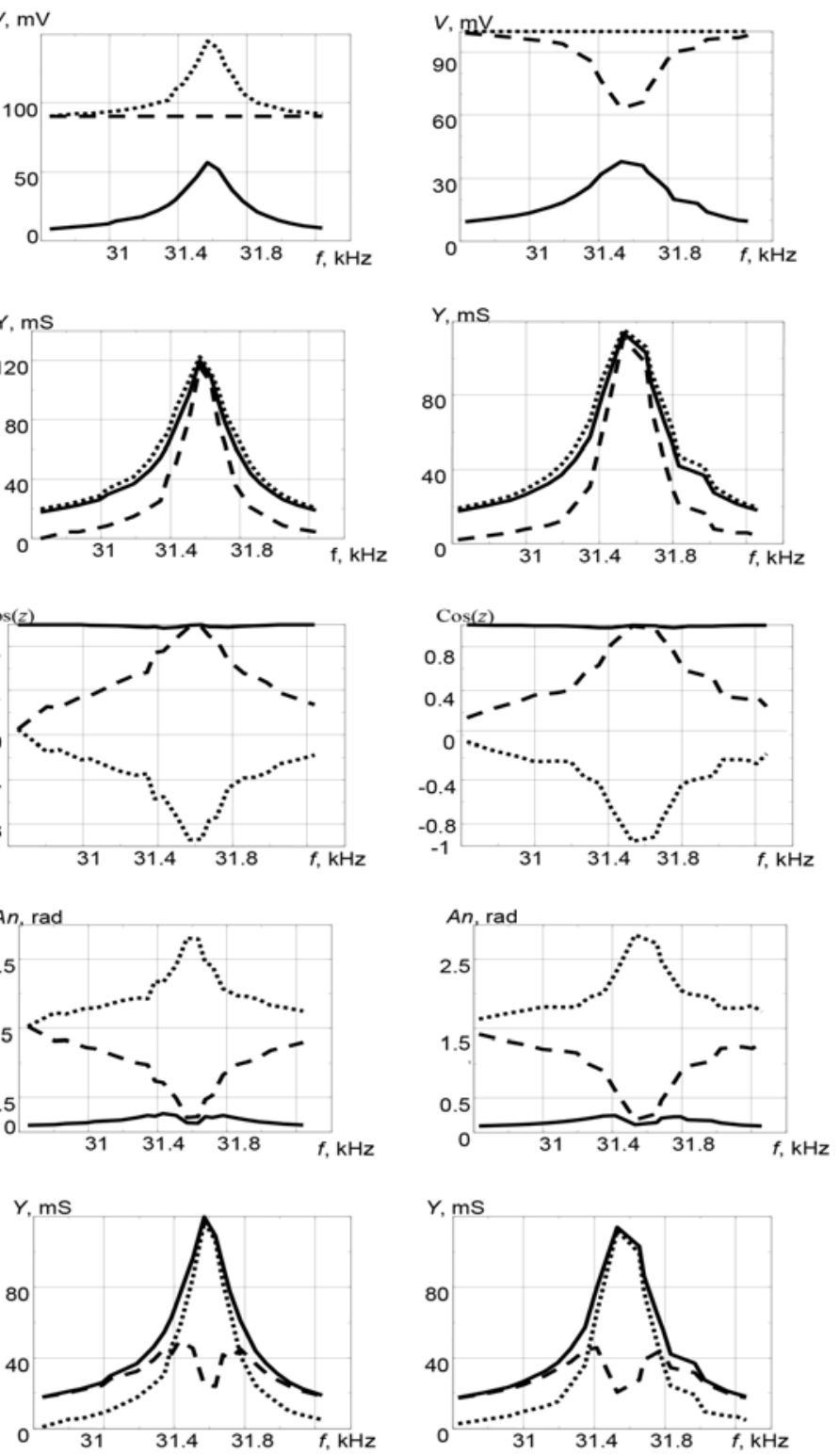

Fig. 2. AFCh of voltages, admittances and angles in piezoelectric disk 
Fig.2 demonstrates AFCh of voltages $U_{p e}, U_{R}$ and $U_{\text {in }}$ (in milliVolts), full admittance (in milliSimens), cosines, angles (in radians) and admittance's components. Graphs are obtained for constant current amplitude $I_{p e}=U_{R} / R=1,89 \mathrm{~mA}$ (left), constant voltage amplitude $U_{p e}=90 \mathrm{mV}$ (centre) and constant input voltage amplitude $U_{i n}=100 \mathrm{mV}$ (right) conditions near first radial resonance of TsTBS-3 disk 66,4 x 3,1 mm with such parameters: $C_{0}=18,5 \mathrm{nF}$, dielectric loss tangent $\varepsilon_{33 m}=0,0085$; mechanical loss tangent $s_{11 \mathrm{~m}}=0,0069$ ); Poisson ratio $v=0,35$; planar EMCF square $k_{\text {po }}^{2}=0,31$ and piezoelectric loss tangent $d_{31 \mathrm{~m}}=0,0076$.

On higher graphs (first row) $U_{p e}$ are shown as interrupted curves, $U_{i n}-$ as dot curves and $U_{R}$ as unbroken lines. Full admittances (second row) are calculated with formulae (15) (unbroken lines), (16) (dot lines) and (17) (interrupted curves). At resonance exact $(15)$ and approximate $(16,17)$ expressions gave the same results. Third and forth rows present cosines of triangle's angles and corresponding angles. Angle $\alpha$ (dot lines) is created by $U_{R}$ and $U_{p e}$, sides. It characterizes a phase shift between piezoelement's current and voltage. Angle $\beta$ (interrupted curves) is created by sides $U_{i n}$ and $U_{R}$. It is according to phase shift between output generator voltage and consuming current. At least, angle $\gamma$ (unbroken lines) is created by sides $U_{\text {in }}$ and $U_{p e}$, i. e. between output generator voltage and sample's voltage. Lower, fifth row presents full $Y$ (unbroken curves), real $G$ (dot lines) and imaginary $B$ (interrupted curves) parts of admittance, calculated with formulae, which give same results or

$$
\begin{aligned}
& \mathrm{G}_{2}=\mathrm{Y}_{\mathrm{pe}} / \sqrt{\left(1+\mathrm{k}^{2}\right),} \\
& \mathrm{B}_{2}=\mathrm{G}_{2} \mathrm{k}, \mathrm{k}=\tan \beta
\end{aligned}
$$

Graphs of Fig.2 show that for small signal appropriate circumstances constant current and constant voltage exhibit same result.

Experimental methodic of loss characteristics determination in our time is such as 50 years ago. At a low frequency (1000 Hz or near) capacity bridge measures inter-electrode capacity $C_{0}$ and $\tan \delta=\varepsilon_{33 m}$. Maxima / minima admittances are used then for calculations of elastic $s_{11 \mathrm{~m}}$ and ptezoelectric $d_{31 m}$ loss tangent with formulae (8) forrods or (14) for disks. Mechanical tangent $s_{11 m}=1 / Q_{m}$ is determined too by bandwidth method from AFCh admittance [25] or transform ratio in piezotransformer transducer method [16]. A piezotransformer transducer method bases on dividing in electrode piezoelement surface one or a number of small parts and in measuring their potentials or charges, which are proportional to inner mechanical stresses.

Plotting a dependence of potentials such transducers in any surface direction we may study a stress state on resonance frequencies. Plotting AFCh of such transducer's potentials $U$ or transform ratio $K_{t}=U / U_{0}\left(U_{0}\right.$ is input voltage) we may determine mechanical quality factor

$$
Q_{m}=\frac{f_{9}}{f_{2}-f_{1}},
$$

where: $f_{0}$ - maximum potential frequency, $f_{2}-f_{1}-$ difference between $-3 \mathrm{db}$ level frequencies, which lie upper and lower $f_{0}$.

It is sufficient difference between constant current and constant voltage loading conditions for high power regime devices, such as radiators, ultrasonic motors or transformers. Recently C.O. Ural et al [33] show that constant voltage regime is surrounded with great nonlinearity while constant current regime don't exhibits its. Data were obtained from longitudinal first mode rectangular PZT-8 plate vibration. Authors consider that there is serious difficulty in determining the electromechanical coupling parameters under a high electric field drive from the admittance curves under a constant voltage condition. With a constant voltage method the resonance spectrum distorts significantly, sometimes exhibiting large hysteresis or a jump of the peak curve upon rising and falling frequency driving. Careful analyze of [33] graphs shows that maxima admittance for constant voltage conditions reach $50 \mathrm{mS}$ only while at constant current it reach $80 \mathrm{mS}$. The maxima admittance frequencies lie in first case in range $55,9-56,1 \mathrm{kHz}$ and in range $56,2-56,4 \mathrm{kHz}$ for second case. It means that power and temperature conditions at constant voltage and constant current regime are not identical. Simple calculations on [33] graphs data (Table. 2, Table 3) show that constant voltage condition differs from constant current condition with maxima power level a number of times.

Table 2. Power's maxima at constant voltage conditions

\begin{tabular}{|l|l|l|l|l|l|l|}
\hline $\mathrm{U}, \mathrm{mV}$ & 100 & 300 & 500 & 800 & 1000 & 1500 \\
\hline $\mathrm{I}, \mathrm{mA}$ & 4,9 & 14,7 & 29,5 & 33,6 & 37 & 40,5 \\
\hline $\mathrm{P}, \mathrm{mW}$ & 0,49 & 4,41 & 11,75 & 26,8 & 37 & 60,7 \\
\hline
\end{tabular}


Table 3. Power's maxima at constant current conditions

\begin{tabular}{|l|l|l|l|l|l|}
\hline$I, \mathrm{~mA}$ & 5 & 10 & 20 & 30 & 40 \\
\hline$U, \mathrm{mV}$ & 71,5 & 131 & 266 & 400 & 558 \\
\hline$P, \mathrm{~mW}$ & 0,36 & 1,31 & 5,33 & 12 & 23,5 \\
\hline
\end{tabular}

To examine the energy loss tangent's influence on vibration characteristics the calculations were provided near maxima admittance / impedance for TsTBS-3 disk 66,4 x 3,1 mm. Formulae (13) were used in complex form (without Bessel function expansions) for dimensionless frequency ranges $2,05-2,1 ; \quad 2,39-2,415, \quad k_{p}^{2}=0,32, \quad s_{11 \mathrm{~m}}=0,007$, $\varepsilon_{33 \mathrm{~m}}=0,0085$, and for three values $d_{31 \mathrm{~m}}=0,0035$; 0,005 and 0,007 . All three admittance curves coincide - dielectric and piezoelectric losses don't influence on resonant vibrations near first resonance. It was obtained such values $Y_{m 0}=132 \mathrm{mS}, Y_{1,2}=93,3$ (on bandwidth ends $-3 \mathrm{~dB}$ level $[25,31]$ ), $x_{0}=2,079$, $Q_{r}=138-148$. Impedance lines differ in amplitude and have such bandwidth method determined qualities $Q_{a}=228,4 ; 184,5$ and 171,4 . In experiment loading resistor near resonance was $11,2 \mathrm{Ohm}$ and near anti-resonance - $20 \mathrm{kOhm}$. It was obtained such results: $Y_{m}=127,1 \mathrm{mS}, Y_{-3 \mathrm{db}}=89,87 \cong 90 \mathrm{mS} ; f_{2}$ $f_{1}=22 / 28^{*} 300=235,7 \quad \mathrm{~Hz} ; \quad Q_{r}=31551 / 235,7=138,8$; $Z_{n}=16,86 \quad \mathrm{kOhm}, \quad Z_{-3 \mathrm{db}}=11,92 \mathrm{kOhm} ; \quad f_{2}$ $f_{1}=31 / 33^{*} 200=187,9 \mathrm{~Hz} ; \quad Q_{a}=36,499 / 187,9=194,2$. The results are in a good matching with calculated data and show that resonant and anti-resonant quality factors differ almost $40 \%$ while in calculations were taken constant value for mechanical quality equal $Q_{m}=143$. It means that conception of constant (frequency independent) values of dielectric, elastic and piezoelectric loss tangent do not conflict with analytic and experimental results.

Independence resonant phenomena upon dielectric and piezoelectric losses was postulated by G.W.Katz [20] for Rozen-type [34] transformer and was used in my papers [17 - 19]

\section{A new methodic for determination coupling and loss coefficients}

The procedure of coupling and loss coefficients determination may be simplified and its accuracy may be increased by calculation of full admittance's AFCh in frequency range near resonance and antiresonance. The methodic is described below on example of thin piesoceramic disk's radial vibrations but it may be provided with similar success for somewhat geometry form elements with famous resonant/anti-resonant determinants. At first the resonance/anti-resonance frequencies and admittances are measured for first and second vibration modes as well as static capacity $C_{0}$ and dielectric loss tangent $\varepsilon_{33 \mathrm{~m}}$. Ratio $f_{r 2} / f_{r 1}$ gives Poisson ratio $v$ $[6,9,13,28]$ and a ratio $f_{a 1} / f_{r 1}$ gives planar EMCF $k_{p}^{2}[6,13,29]$. Mechanical quality $Q_{m}$ is found by piezotransformer transducer method $[13,29]$ or in another way and elastic loss tangent $s_{11 \mathrm{~m}}$ is found as

$$
\mathrm{s}_{11 \mathrm{~m}}=\frac{1}{\mathrm{Q}_{\mathrm{m}}} .
$$

Values $s_{11 \mathrm{~m}}, \varepsilon_{33 \mathrm{~m}}, v, C_{0}$ and $k_{p}^{2}$ as well as $d_{31 \mathrm{~m}} \approx \varepsilon_{33 \mathrm{~m}}$ (this parameter is not known at first and its value is taken randomly) enter to PC. Admittance AFCh in first resonance vicinity is plotted. A ratio maxima/minima frequency is compared with measured one and $k_{p}^{2}$ is correlated. Admittance AFCh in first resonance vicinity is plotted again and $s_{11 \mathrm{~m}}$ is correlated. When calculated values of $Y_{m}$ and $f_{a 1} / f_{r 1}$ coincide with measured ones it may be go to anti-resonant region and to find a piezoelectric loss tangent. Author's experience shows that good results are obtaining with three or four iterative steps. For first step any hypothetic data may be taken of cause.

Let us look an example (Fig. 3). To admittance calculation convenience it is doubt to present $\omega C_{0}$ as

$$
\omega \mathrm{C}_{0}=\frac{2 \pi \mathrm{f}_{0} \mathrm{C}_{0} \mathrm{x}}{\mathrm{x}_{0}}=\mathrm{ax}, \quad \mathrm{a}=\frac{2 \pi \mathrm{f}_{0} \mathrm{C}_{0}}{\mathrm{x}_{0}},
$$

here: $f_{0}$ is resonance frequency, $x_{0}$ - dimensionless resonant frequency (first resonant determinant root), $x$ - running dimensionless frequency.

The first step (Fig 3, a) was made with next data (disk TsTBS-3 $66,4 \times 3,1 \mathrm{~mm}$ size) $a=1.77$, $v=0,35, \varepsilon_{33 \mathrm{~m}}=0,0085, k_{p}^{2}=0,2, s_{11 \mathrm{~m}}=0,01 ; d_{31 \mathrm{~m}}=0,01$ Measured frequency ratio was $36502 / 31560=1,156$, calculated $-2,27 / 2,08=1,091$. It is necessary to increase $k_{p}{ }^{2}$ value. For the case $k_{p}{ }^{2}=0,3 \quad$ (Fig 3, b) frequency ratio is $2,38 / 2,08=1,144$, and for case of $k_{p}{ }^{2}=0,32$ (Fig 3, c) $f_{a 1} / f_{r 1}=2,4 / 2,08=1,154$. This result is almost equal to measured one. The calculated $92 \mathrm{mS}$ and measured $131 \mathrm{mS}$ maxima admittance differ in 1,42 times and elastic loss tangent must be decreased to $\mathrm{s} 11 \mathrm{~m}=0,007$ (Fig 3, d). Now calculated and experimental admittances at resonant frequency are agreed and may be work next step and go to admittance minima (Fig 3,e). 


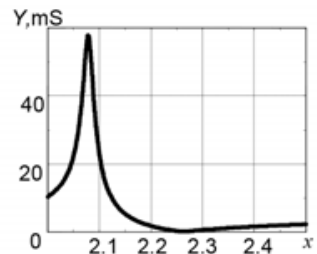

a)

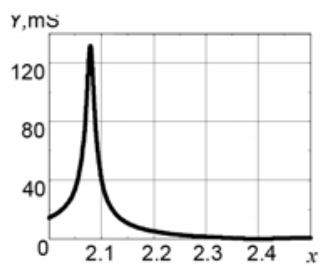

d)

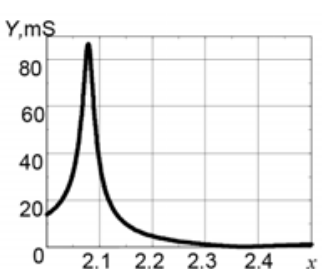

b)

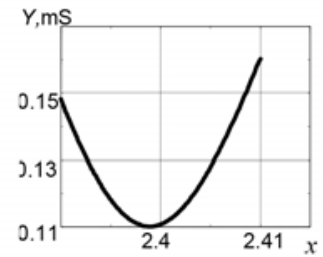

e)

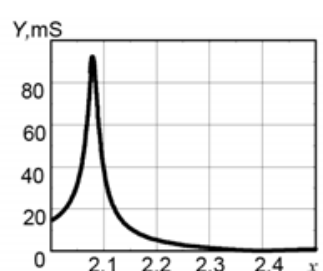

c)

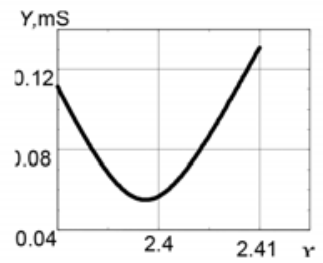

f)

Fig. 3. Steps of iterative methodic

Graph's minimum is $0,11 \mathrm{mS}$ but in experiment it is $0,0587 \mathrm{mS}$ for loading resistor value $20 \mathrm{kOhm}$. Decreasing of piezoelectric loss tangent to a level $d_{31 \mathrm{~m}}=0,0035$ decreases admittance minimum to value $Y_{n}=0,056 \mathrm{MS}(\mathrm{Fig} 3, f)$, that is in a good matching with an experiment

As a result of describing investigations for called higher disk 66,4×3,1 mm from TsTBS-3 material the next refined data were obtained: $k_{p}^{2}=0,32, s_{11 \mathrm{~m}}=0,007, d_{31 \mathrm{~m}}=0,0035, \varepsilon_{33 \mathrm{~m}}=0,0085$.

Similar iterative methodic was used by J.G. Smith [30] for accurate determination of real and imaginary parts of materials coefficients.

On the base of $f_{m}, C_{0}, k_{p}{ }^{2}, \varepsilon_{33}$ and density $\rho$ it may be determine a number of parameters of piezoceramics. This is transverse coupling coefficient $k_{31}$, piezomodulus $d_{31}$, elastic compliance $s_{11}$ and piezoconstant $g_{31}[9,13,28]$

$$
k_{31}^{2}=\frac{(1-v)}{2} k_{p}^{2}, \quad \frac{1}{s_{11}}=\frac{\pi^{2} d^{2} f_{m}^{2}\left(1-v^{2}\right) \rho}{\kappa_{1}^{2}}, \quad d_{31}=k_{31} \sqrt{\varepsilon_{33} s_{11}}, g_{31}=\frac{d_{31}}{\varepsilon_{33}} .
$$

Here: $d$ is plate diameter, $\kappa_{1}-$ root of resonance determinant (14).

Dielectric constant is determined from a plate capacitor formula

$$
\varepsilon_{33}=4 \mathrm{hC}_{0} / \pi \mathrm{d}^{2}
$$

and for our disk it is $\varepsilon_{33}=\frac{4 * 2 * 10^{-3 *} 51,1^{*} 10^{-9}}{\pi * 100 * 100 * 10^{-6}}$ $\mathrm{F} / \mathrm{M}=130,2 * 10^{-10} ; \mathrm{F} / \mathrm{M}=1471 \varepsilon_{0}$.

\section{Results and discussion}

Vibrating system for any piezoelectric resonator may be presented an equivalent electrical network in which in parallel to static inter-electrode capacity $C_{0}$ is connected a series branch, consisting from inductance $L$, capacitor $C$ and resistor $r$ (this resistor symbolizes elastic energy losses). Such system is called in radio-engineering as third view circuit [10]. A voltage resonance in series circuit corresponds to resonant frequency when $r=1 / Y_{m}$. And the current resonance in parallel circuit corresponds to anti-resonant frequency. This parallel circuit consists from inductance $L$ and equivalent condenser $C^{\prime}$, which created by $C_{0}$ and $C$ in series $C^{\prime}=C_{0} C /\left(C_{0}+C\right)$.

In radio-engineering quality $Q$ of resonant system determined as ratio of stored in circuit energy $E_{\text {stor }}$ to loss energy $E_{\text {dis.av }}$ which dissipate during vibration period. It expressed with circuit parameters in such a way $[10,36]$

$\mathrm{Q}=2 \pi \frac{E_{\text {stor }}}{E_{\text {dis.av }}}=\frac{\rho}{r}=\frac{2 \pi f_{0} L}{r}=\frac{1}{2 \pi f C}, \rho=\sqrt{\frac{L}{C}}, f_{0}=\frac{1}{2 \pi \sqrt{L C}}$,

is wave circuit resistance, $r$ - loss resistor, $f_{0}-$ resonant frequency, $L$ and $C$ - circuit inductance and capacity.

The next formulae may be obtained

$$
C=\frac{1}{\rho \omega}=\frac{1}{2 \pi f_{0} \rho}=\frac{1}{2 \pi f_{0} Q_{r} r}, L=\frac{\rho}{\omega}=\frac{\rho}{2 \pi f_{0}}=\frac{Q_{r} r}{2 \pi f_{0}} \text {. }
$$

In our disk $66,4^{*} 3,1 \mathrm{~mm}$, loading on $11,2 \mathrm{Ohm}$, loss resistor was $r=7,87 \mathrm{Ohm}, \mathrm{Qr}=138,8$ and $\rho=\mathrm{Qr}^{*} \mathrm{r}=1092 \mathrm{Ohm}, \mathrm{f} 0=3,155^{*} 104, \mathrm{C} 0=1,849^{*} 10-8$ F. Substituting these data in (27) we may obtain $C$ $=1 /\left(2 * 3,14^{*} 1,092^{*} 3,155^{*} 107\right) \mathrm{F}=1 /\left(2,164^{*} 108\right) \mathrm{F}=$ $=4,62 * 10-9 \quad \mathrm{~F}, \quad \mathrm{~L}=1092 /\left(2^{*} 3,14 * 3,155^{*} 104\right)=$ $=5,51 * 10-3 \mathrm{Hn}$. Parallel circuit capacity is $\mathrm{C}^{\prime}=\mathrm{C}^{*} \mathrm{C} 0$ $/(C+C 0)=4,62 * 18,49 /(4,62+18,49) * 10-9$ 
$F=3,696 * 10-9$ F. Parallel resonance frequency, wave resistance and anti-resonant quality factor are $f_{n}=3,528 * 10^{4} \mathrm{~Hz}, \rho==1221$ Ohm, $Q_{a}=1221 / 7,87=155,1$. Measured values were next $36499 \mathrm{~Hz}, Q_{a}=194,2$.

Why so great discrepancy between calculated and measured values of qualities and anti-resonant frequencies exists? The reason lies in clamped capacity and electromechanical coupling factor's val-
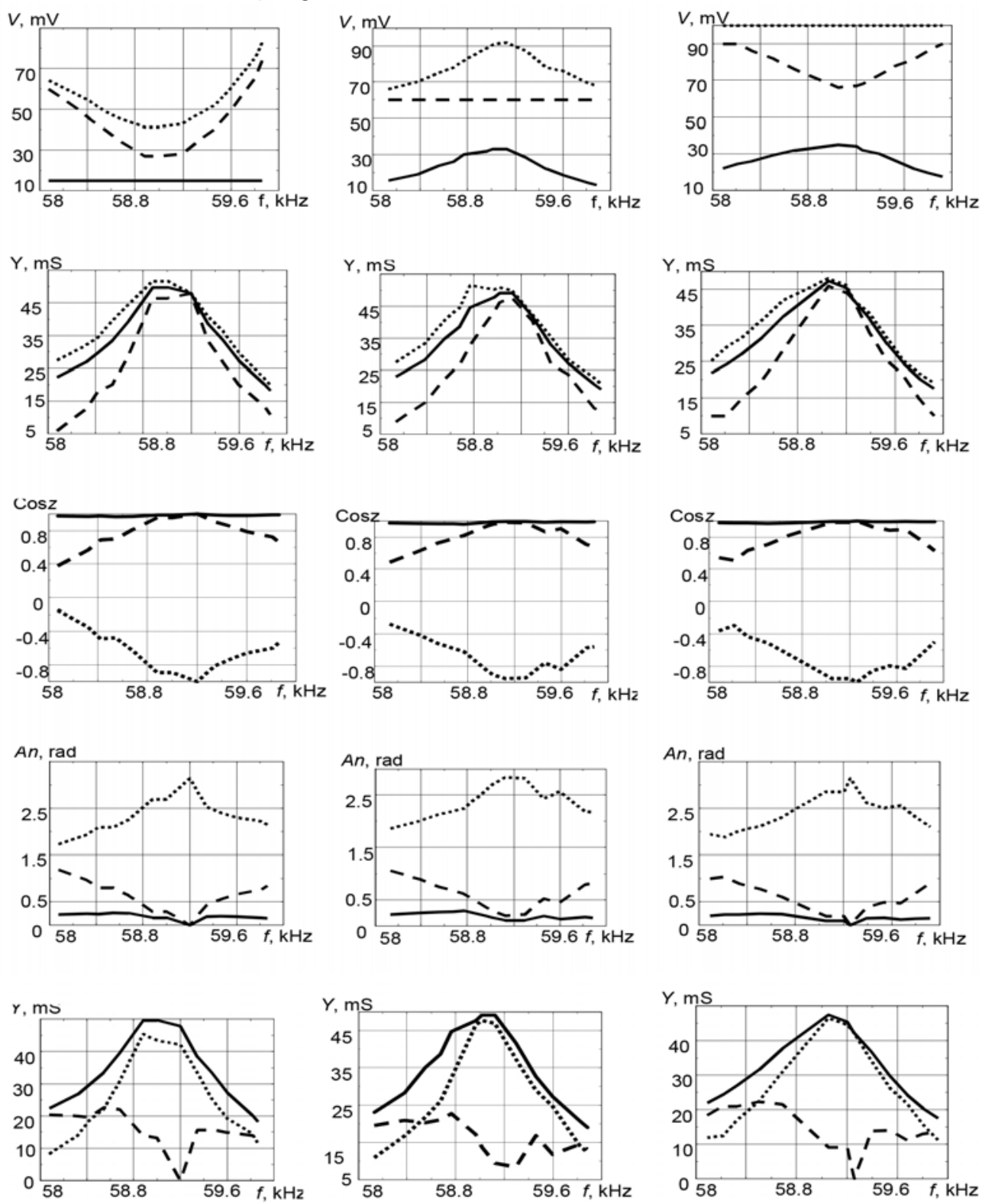

Fig. 4. AFCh of voltages, admittances and angles in equivalent network

Fig 4 rerpresents a result of modeling equivalent network with $L=0,4 \mathrm{mHn}, C_{0}=9,579 \mathrm{nF}, C=$ $=1,814 \mathrm{nF}$ and $R=11,2 \mathrm{Ohm}$ Graphs are plotted for voltages, input admittance, cosines, angles and real/imaginary admittance. Graphs are obtained for constant current $I_{e q}=U_{R} / R=15 \mathrm{mV} / 11,2 \mathrm{Ohm}=$ $=1,34 \mathrm{~mA}$ (left), constant voltage $U_{e q}=60 \mathrm{mV}$ (cen- tre) and constant input voltage $U_{i n}=100 \mathrm{mV}$ (right) conditions near series circuit resonance.

On higher graphs (first row) $U_{e q}$ are shown as interrupted curves, $U_{\text {in }}$ - as dot curves and $U_{R}$ as unbroken lines. Full admittances (second row) are calculated with formulae (15) (unbroken lines), (16) (dot lines) and (17) (interrupted curves). Third and 
forth rows present cosines of triangle's angles and corresponding angles. Angle $\alpha$ (dot lines) is created by $U_{R}$ and $U_{\text {eq, }}$, sides. It characterizes a phase shift between circuit's current and voltage. Angle $\beta$ (interrupted curves) is created by sides $U_{\text {in }}$ and $U_{R}$. It is according to phase shift between output generator voltage and consuming current. At least, angle $\gamma$ (unbroken lines) is created by sides $U_{\text {in }}$ and $U_{e q}$, i. e. between output generator voltage and equivalent circuit's voltage. Lower, fifth row presents full $Y$ (unbroken curves), real $G$ (dot lines) and imaginary $B$ (interrupted curves) parts of circuit admittance, calculated with formulae (19) or (20). Graphs of Fig.4 in general are similar to lines of Fig 2. Both show that for small signal appropriate circumstances constant current and constant voltage exhibit same result.

\section{Conclusions}

Analysis of the efficiency of excitation at resonance/anti-resonance frequencies was made by many authors. It was established $[25,26]$ that the character of the interrelation of quality factors is determined mainly by the imaginary part of electromechanical coupling factor whose influence is the most essential at the fundamental anti-resonance frequency. Greater value of the anti-resonance quality factor in respect to the resonance quality factor makes it preferable to provide the top mechanical displacement amplitude. The piezoelectric loss tangent causes changes not only in the total energy losses, but also influences on the distribution of the thermal losses in the volume.

The high power behavior of piezotransducers is very sensitive to loading conditions and differs for 1) constant voltage, 2) constant current, 3) constant vibration velocity and 4) constant input power.

The results [33] clearly concluded that compared to the resonance, the anti-resonance exhibits a higher mechanical quality factor $Q_{m}$ and the same vibration amplitude/velocity under a smaller input electrical power and lower heat generation. This may suggest a superiority of the antiresonance application, typically for ultrasonic motor and transformer.

The [33] results may be explained in such a way. When piezoelectric sample is excited by constant voltage the instantaneous power in sample is increased at resonance frequency in many times in respect to off-resonant case. And when sample is excited by constant current the instantaneous power in sample is decreased at resonance frequency in that ratio. Thus, the reason of curve nonlinearity at constant voltage and its absence at constant current is lower level of an instantaneous power.

Modeling of piezoelectric element vibrations by $R, C, L$ famous value elements permits to study these influence on resonant/anti-resonant frequencies as well as full conductivities.

Accounting only constant values of dielectric, elastic and piezoelectric loss tangents in calculations do not conflicts with analytic and experimental results.

\section{Acknowledgements}

The author thanks S.P. Timoshenko Institute of Mechanics, Nat. Acad. Sci. of the Ukraine for supports these investigations. He would wish like to acknowledge Prof O.I. Bezverkhy (Ukraine) for useful consultations and $\mathrm{Dr}$ A.V. Mezheritsky (USA) for important information.

\section{References}

1. Berlincour D.A., Curran D.R. and Jaffe H. Piezoelectric and piezomagnetic materials and their function in transducers. In Physical acoustics, vol.1. W.P. Mason ed. New York, Academic Press, 1964, pt. A. pp. $169-270$.

2. Butterworth $S$. On electrically maintained vibrations // Proc. Phys. Soc. (London). - 1915. Vol. 27. - pp. $410-424$.

3. Cady W.G. Theory of longitudinal vibrations of viscous rods // Phys. Rev. - 1922. - Vol. 19, no 1. - pp. $1-6$.

4. Dye D.E. The piezoelectric quartz resonator and its equivalent circuit // Proc. Phys. Soc. (London). - 1926. - Vol. 38. - pp. 399 - 453.

5. Dyke Van S. The electric network equivalent of piezoelectric resonators // Phys. Rev. - 1925. Vol. 25. - p. 895(A).

6. Glozman I.A. Pjezokeramika [Piezoceramics], Moscow, Energhiya, 1972. - 288 p. (Rus)

7. Holland R. Representation of dielectric, elastic and piezoelectric losses by complex coefficients // IEEE Trans. SU. - 1967. - Vol. SU-14. pp.18- 20.

8. IRE Standards on Piezoelectric Crystals: Measurements of Piezoelectric Ceramics. 1961 // Proc. IRE. - 1961. - Vol. 49. - pp. 1161 1169.

9. Jaffe B., Cook W.R. and Jaffe H. Piezoelectric ceramics. - London, Academic Press: 1971.

10. Kalashnikov A.M. and Stepuk Ya.V. Osnovy radiotechniki I radiolokatsiji, koljebatjel"nyje sistjemy [Bases of radio-engineering and radiolocation, vibrating systems]. Moscow, Voyeniz, 1962. 368 p. (Rus) 
11. Karlash V.L. Vlijanije dissipatsiyi energhiyi na amplitudno-chastotnyje charakteristiki polnoy provodimosti tonkogo pjezokeramidheskogo diska [Influence of energy dissipation on amplitude-frequency characteristics of thin piezoceramic disk full conductivity] // Electrichestvo. 1984. -no 4. - pp. 59 - 61. (Rus)

12. Karlash V.L. Dissipatsiya energhiyi pri koljebaniyakh tonkikh pjezokeramidheskikh kruglykh plastin [Energy dissipation at vibrations of thin piezoceramic circular plates] // Prikladnaya mechanika - 1984. - Vol. 20, no 5. - pp. 77 - 82. (Rus)

13. Karlash V.L. Resonant electromechanical vibrations of piezoelectric plates // Int. Appl. Mech. - 2005. - Vol. 41, no 7. - pp. 709 - 747.

14. .Karlash V.L. Longitudinal and lateral vibrations of a plate piezoceramic transformer // U. J. Phys. - 2006. - Vol. 51, no 10. - pp. 985 991.

15. Karlash V.L. Particularities of amplitudefrequency characteristics of admittance of thin piezoceramic half-disk // Int. Appl. Mech. 2009. - Vol. 45, no10. - pp. 647 - 653.

16. Karlash V.L. and Ulitko A.F. Metod issljedovanija medhanicheskilh naprjazheniy $\mathrm{v}$ koljebljushchikhsja pjezokeramidheskikh tjelakh [Method of mechanic stress investigation in vibrating piezoceramic bodies] // Eelectrichestvo. - 1976. - no 11. - pp. 82 - 83. (Rus)

17. Karlash V.L. Electroelastic vibrations and transformation ratio of a planar piezoceramic transformer // J. Sound Vib. - 2004. - Vol. 277. -pp. $353-367$.

18. .Karlash V.L. Longitudinal and lateral vibrations of a planar piezoceramic transformer // Jpn. J. Appl. Phys. - 2005. - Vol. 44, no 4A. - pp. 1852 - 1856.

19. Karlash V.L. Planar electroelastic vibrations of piezoceramic rectangular plate and half-disk // Int. Appl. Mech. - 2007. - Vol. 43, no 5. - pp. $547-553$.

20. Katz H.W. (ed) Solid State Magnetic and Piezoelectric Devices/ New York, Willey, - 1959.

21. Land C.E., Smith G.W and Westgate C.R. The dependence of small-signal parameters of the ferroelectric ceramic resonators upon state of polarization // IEEE Trans. Sonics and Ultrasonics. - 1964. Vol. SU-11. - pp. 8 -19.

22. Mason W.P. Location of hysteresis phenomena in Rochelle salt // Phys. Rev. - 1940. - Vol. 58. - pp. $744-756$.

23. Martin G.E. Dielectric, piezoelectric and elastic losses in longitudinally polarized segmented ceramic tubes // U.S. Navy J. Underwater Acoustics. - 1965. - Vol. 15. - pp. 329-332.

24. Mezheritsky V. Electrical measurements of a high-frequency, high-capacitance piezoceramic resonator with resistive electrodes // IEEE Trans UFFC, 2005, Vol. 52, no 8, pp. 1229 1238.

25. Mezheritsky A.V. Quality factor of piezoceramics, Ferroelectrics, 2002, Vol. 266, pp. 277 304.

26. Mezheritsky A.V. Elastic, dielectric and piezoelectric losses in piezoceramics; how it works all together // IEEE Trans UFFC. - 2004. - Vol. 51, no 6. - pp. $695-797$.

27. Quimby S.L. On the experimental determination of the viscosity of vibrating solids // Phys. Rev. -1925. - Vol. 38. - pp. $568-582$.

28. .Shul'ga N.A. and Bolkisev A. M. Koljebaniya pjezoelektridheskikh tjel [The Vibrations of Piezoelectric Bodies] / Kiev, Naukova dumka,. 1990. (Rus)

29. Shul'ga M.O. and Karlash V.L. Rezonansni elektromekhanichni kolyvannja pjezoelektridheskikh plastyn [Resonant electromechanic vibrations of piezoelectric plates] /, Kyiv, Naukova dumka, - 2008. 272 p.(Ukr)

30. Smith J.G. Iterative method for accurate determination of real and imaginary parts of materials coefficients of piezoelectric ceramics // IEEE Trans. SU. - 1976. - Vol. SU-23, no 6. pp. $393-402$.

31. Uchino $K$. and Hirose S. Loss mechanisms in piezoelectrics: how to measure different losses separately // IEEE Trans UFFC. - 2001. -Vol. 48, no1 pp. $307-321$

32. Uchino K., Zheng J.H., Chen Y.H. et al Loss mechanisms and high power piezoelectrics .J. Mat. Sci - 2006. - Vol. 41, pp 217 - 228.

33. Ural S.O., Tunodemi S., Zhuang Yu. and Uchino $K$. Development of a high power piezoelectric Characterization system and its application for resonance/antiresonance mode characterization. - Jpn. J. Appl. Phys. - 2009. Vol. 48056509

34. US Patent 4399921954 / Rosen C. A.29.06.1954.

35. Voigt $W$. Lehrbuch der kristallphysik. Leipzig , B.G.Teubner.-1910

36. Zherebtsov I.P. Radiotekhnika [Radioengineering] Moscow, Svyaz' - Sov. Radio. 1965. - 656 p. (Rus)

Поступила в редакцию 26 декабря 2013 г. 
УДК 534.121.1

В.Л. Карлаш, д-р.тех.наук

Інститут механіки ім. С.П. Тимошенко НАН України, вул. Нестерова, 3, м. Київ, 03057, Україна, e-mail: karlashv@ukr.net.

\section{Втрати енергії в п'єзокерамічних резонаторах і їх вплив на характеристики коливань}

Стаття присвячена анадізу сучасних досягнень у проблемі втрат енергії в п'єзокерамічних резонаторах. Паралельно презентується нова проста методика експериментального визначення коефіцієнтів втрат енергії та зв'язку і подається думка автора, чому механічна добротність на резонансі та антирезонансі є різною. Причина полягає у „затиснутій” ємності та у величині коефрічієнта електромеханічного зв'язку. Чим кращий електромеханічний зв'язок, тим дужче „затиснута” ємність і тим вищий ї̈ вплив на антирезонансну частоту й добротність. Бібл. 36, рис. 4., табл. 3.

Ключові слова: п'єзокерамічні резонатори, втрати енергії, електромеханічні коефріцієнти зв'язку, резонансні / анти-резонансні механічні якості.

УДК 534.121.1

В.Л. Карлаш, д-р.тех.наук

Институт механики им. С.П. Тимошенко НАН Украины,

ул. Нестерова, 3, г. Киев, 03057, Украина, e-mail: karlashv@ukr.net.

\section{Потери энергии в пьезокерамических резонаторах и их влияние на характеристики колебаний}

Статья посвящена анализу современных достижений в проблеме потерь энергии в пьезокерамических резонаторах. Параллельно презентуется новая простая методика экспериментального определения коэфрфициентов потерь энергии и святи и приводится мнение автора, почему механическая добротность на резонансе и антирезонансе разная. Причина состоит 8 «зажатой» емкости и в величине коэфрфициента электромеханической связи. Чем лучше электромеханическая связь, тем сильнее «зажата» емкость и тем выше ее влияние на антирезонансную частоту и добротность. Библ. 36, рис. 4., табл. 3.

Ключевые слова: пьезокерамические резонаторы, потери энергии, электромеханические коэфффициенты связи, резонансные/анти-резонансные механические качества.

\section{Список использованных источников}

1. Berlincour D.A., Curran D.R. and Jaffe H. (1964), «Piezoelectric and piezomagnetic materials and their function in transducers». In Physical acoustics, Vol.1. W. P. Mason ed. New York, Academic Press, pt. A. pp. $169-270$.

2. Butterworth S. (1915), "On electrically maintained vibrations". Proc. Phys. Soc. (London), Vol. 27, pp. $410-424$.

3. Cady W.G. (1922), "Theory of longitudinal vibrations of viscous rodsy". Phys. Rev., Vol. 19, no 1, pp. 1 -6 .

4. Dye D.E. (1926), "The piezoelectric quartz resonator and its equivalent circuit". Proc. Phys. Soc. (London), Vol. 38, pp. $399-453$.

5. Dyke Van S. (1925), "The electric network equivalent of piezoelectric resonators". Phys. Rev., Vol. 25, p. 895(A).

6. Glozman I.A. (1972), "Pjezokeramika [Piezoceramics]”. Moscow, Energhiya. P.288. (Rus)

7. Holland R. (1967), "Representation of dielectric, elastic and piezoelectric losses by complex coefficients". IEEE Trans. SU., Vol. SU-14. pp.18-20. 
8. "IRE Standards on Piezoelectric Crystals: Measurements of Piezoelectric Ceramics", (1961). Proc. IRE. Vol. 49, pp. 1161 - 1169.

9. Jaffe B., Cook W.R. and Jaffe H. (1971), "Piezoelectric ceramics". London, Academic Press:.

10. Kalashnikov A.M. and Stepuk Ya.V. (1962), "Bases of radio-engineering and radiolocation vibrating systems", Moscow, Voyeniz, p. 368. (Rus)

11. Karlash V.L. (1984), "Influence of energy dissipation on amplitude-frequency characteristics of thin piezoceramic disk full conductivity", Electrichestvo, no 4, pp. 59 - 61. (Rus)

12. Karlash V.L. (1984), "Energy dissipation at vibrations of thin piezoceramic circular plates", Prikladnaya mechanika, Vol. 20, no 5. pp. 77 - 82. (Rus)

13. Karlash V.L. (2005), "Resonant electromechanical vibrations of piezoelectric plates", Int. Appl. Mech., Vol. 41, no 7, pp. $709-747$.

14. .Karlash V.L. (2006), "Longitudinal and lateral vibrations of a plate piezoceramic transformer", U.J. Phys., Vol. 51, no 10, pp. $985-991$.

15. Karlash V.L., (2009), "Particularities of amplitude-frequency characteristics of admittance of thin piezoceramic half-disk”, Int. Appl. Mech., Vol. 45, no10, pp. $647-653$.

16. Karlash V.L. and Ulitko A.F. (1976), "Method of mechanic stress investigation in vibrating piezoceramic bodies", Eelectrichestvo, no 11, pp. 82 - 83. (Rus)

17. .Karlash V.L. (2004), "Electroelastic vibrations and transformation ratio of a planar piezoceramic transformer", J. Sound Vib., Vol. 277, pp. 353 - 367."

18. .Karlash V.L. (2005), "Longitudinal and lateral vibrations of a planar piezoceramic transformer", Jpn. J. Appl. Phys., Vol. 44, no 4A, pp. $1852-1856$.

19. Karlash V.L. (2007), "Planar electroelastic vibrations of piezoceramic rectangular plate and half-disk", Int. Appl. Mech., Vol. 43, no 5, pp. 547 - 553.

20. Katz H.W. (1959), "Solid State Magnetic and Piezoelectric Devices", New York, Willey.

21. Land C.E., Smith G.W and Westgate C.R. (1964), "The dependence of small-signal parameters of the ferroelectric ceramic resonators upon state of polarization”, IEEE Trans. Sonics and Ultrasonics, 1964. Vol. SU-11. - pp. 8 -19.

22. Mason W.P. (1940), "Location of hysteresis phenomena in Rochelle salt", Phys. Rev., Vol. 58, pp. 744 $-756$.

23. Martin G.E. (1965), "Dielectric, piezoelectric and elastic losses in longitudinally polarized segmented ceramic tubes", U.S. Navy J. Underwater Acoustics, Vol. 15, pp. $329-332$.

24. Mezheritsky V. (2005), "Electrical measurements of a high-frequency, high-capacitance piezoceramic resonator with resistive electrodes", IEEE Trans UFFC, Vol. 52, no 8, pp. 1229 - 1238.

25. Mezheritsky A.V. (2002), "Quality factor of piezoceramics", Ferroelectrics, Vol. 266, pp. $277-304$.

26. Mezheritsky A.V. (2004), "Elastic, dielectric and piezoelectric losses in piezoceramics; how it works all together", IEEE Trans UFFC, Vol. 51, no 6, pp. 695 - 797.

27. Quimby S.L. (1925), "On the experimental determination of the viscosity of vibrating solids", Phys. Rev., Vol. 38, pp. $568-582$.

28. .Shul'ga N. A. and Bolkisev A. M. (1990), "The Vibrations of Piezoelectric Bodies", Kiev, Naukova dumka. (Rus)

29. Shul'ga M.O. and Karlash V.L (2008), "Resonant electromechanic vibrations of piezoelectric plates", Kyiv, Naukova dumka, p. 272.(Ukr)

30. Smith J.G. (1976), "Iterative method for accurate determination of real and imaginary parts of materials coefficients of piezoelectric ceramics", IEEE Trans. SU., Vol. SU-23, no 6, pp. $393-402$.

31. Uchino K. and Hirose S. (2001), "Loss mechanisms in piezoelectrics: how to measure different losses separately", IEEE Trans UFFC, Vol. 48, no1, pp. 307 - 321

32. Uchino K., Zheng J. H., Chen Y. H. (2006), "et al Loss mechanisms and high power piezoelectrics", J. Mat. Sci, Vol. 41, pp $217-228$.

33. Ural S.O., Tunodemi S., Zhuang Yu. and Uchino K., (2009), "Development of a high power piezoelectric Characterization system and its application for resonance/antiresonance mode characterization", Jpn. J. Appl. Phys., Vol. 48056509.

34. Rosen C.A. (1954), US Patent 439992.

35. Voigt W. (1910), "Lehrbuch der kristallphysik", Leipzig, B.G.Teubner.

36. Zherebtsov I.P. (1965), "Radio-engineering”, Moscow, Svyaz', Sov. Radio, 656 p. (Rus) 